\section{From Narativity to Criticality: Developing EFL Learners' Critical Thinking Skills through Short Narratives/Stories Reading}

\author{
Ashkan Pashangzadeh (Corresponding author) \\ Dept. of English Language and Literature, Faculty of Humanities, Arak University \\ Arak 38156-8-8349, PO. Box: 879, Iran \\ E-mail: ashkan.pashang@yahoo.com or a.pashangzadeh@aol.com
}

Moussa Ahmadian

Dept. of English Language and Literature, Faculty of Humanities, Arak University Arak 38156-8-8349, PO. Box: 879, Iran

E-mail: M-ahmadian@araku.ac.ir

Hooshang Yazdani

Dept. of English Language and Literature, Faculty of Humanities, Arak University Arak 38156-8-8349, PO. Box: 879, Iran

E-mail: H-yazdani@araku.ac.ir

Received: January 28, 2016 Accepted: March 26, 2016 Published: March 29, 2016

doi:10.5296/elr.v2i1.8952 URL: http://dx.doi.org/10.5296/elr.v2i1.8952

\begin{abstract}
Regarding the ever presence of narratives/stories in almost all aspects of human beings' lives and the significance of Critical Thinking (CT) as an important factor in directing students to avenues of success in both educational and non-educational contexts, this study attempted to investigate the effectiveness of reading short narratives in EFL learners' CT skills development. To this end, 59 undergraduate EFL learners majoring in English translation participated in the study. Taking into consideration the participants' homogeneity in language
\end{abstract}


proficiency and CT skills, 54 were finally selected and put into two experimental and control groups, namely, Narrative and Non-narrative groups, and 27 participants in each group. Short narrative and non-narrative (expository) texts, as elicitation tasks, were used for Narrative and Non-narrative groups respectively. Using a learner oriented approach, communicative reading strategies were incorporated into the course design for both groups. Statistical results, under the influence of 12 treatment sessions, indicated the out-performance of Narrative group, in comparison with Non-narrative one, from the pretest to the post-test (California Critical Thinking Skills Test, CCTST). Possible explanations for the difference in participants' CT skills and potential pedagogical implications of the findings for language learning and teaching have been discussed.

Keywords: Critical thinking skills, Narrative texts, Non-narrative texts, EFL learners, Learner-oriented approach

\section{Critical Thinking}

The pervasive effects of CT on personal and social life, throughout the long journey of humankind from the oldest human civilizations to the modern civilized societies, by and large, have almost ever been an ongoing debate among scholars coming from different national and cultural backgrounds (Paul, Elder, \& Bartell 1997; Descartes, 2006). It appears that the necessity of CT has always been unquestionable in the arena of human life. But, in the world of today, incredible speed of scientific and technological developments has turned CT into a more vital necessity for current generation who needs more education, in comparison with older ones, since, it seems through a fast-changing contemporary scenario, the world both in educational and non-educational areas has become a more complicated and sophisticated place to live in. Only a few minutes of internet searching can provide everyone with an enormous wealth of available information which creates a 'paralysis of analysis' as we think in what manner to make our selection of data from existing ever-expanding databases (Davidson, 1996 cited in Halpern, 2003).

Regarding the importance of $\mathrm{CT}$, there are number of studies through which critical thinking and critical thinker have been characterized and portrayed (Brookfield, 1987; Facione, 2013; Ferrett, 1997; Halpern, 2003; Kurfiss, 1988; and Smith, 2002 to mention but a few). Wade (2008) expresses that the main purpose of education is to help students learn to think deeply in confrontation with problems, challenges, tasks, and dilemma. Facione and Facione (1994) state that learning how to learn and learning how to think, in today's world, seems absolutely necessary. Facione and Facione (1994, p. 3) eloquently argue that 'fact-loading memorizers who cannot analyze information, draw out the implications, evaluate the cogency of arguments, and explain how they arrived at their results will not survive in the competitive economic and political arenas of this or the next century.' The practical integration of CT goals in educational contexts in general and in teaching and learning foreign/second languages in particular seems to be a new avenue of research.

\section{Critical Thinking in EFL/ESL Contexts}

Educational settings in general and second/foreign language classes in particular, due to the wealth of materials and interactive methodologies, appear to be of high appropriateness for critical thinking instructions. Critical thinking abilities can help the formation of 
self-awareness which enables EFL learners to recognize the existing associations between emotions and thoughts. At first glance, it seems that thought and emotion are independent from each other but careful analyses show that there are some kinds of dependencies between them. Emotional side of language learners plays an important role in the processes of learning, 'learners may bring learned indifference, irrational fears, acquired hostility, and inflexible ideas into the classroom so their learning is limited to the surface' (Paul \& Elder, 2002 quoted in Jose, 2013 p. 99). Through emphasis on self-awareness, second/foreign language teachers can help their students to understand themselves and their surroundings as much as possible. As Üstünlüoglu (2004, p. 3) stipulates, 'by means of interactive approaches and materials, teachers can help students be aware of their perceptions, assumptions, prejudices, and values, and can help students break old habits to construct a new point of view.' Awareness development in L2 learners may help them to reinforce positive attitude toward the members of L2 culture and create an interest to understand cultural aspects of L2 community and to empathize with the native language group. Positive attitudes may lead to increased motivation to learn a second language (Brown, 2006). It will definitely demand hard effort, but students will enjoy discovering themselves for sure as they learn a new language.

Regarding five agreed upon CT skills subscales including Evaluation, Analysis, Inference, Deductive reasoning, and Inductive reasoning (Facione, 2013), proficient readers seemingly in a similar way make use of these skills in order to comprehend while reading a text (Grabe, 2009). According to Grellet (1981), successful readers do not focus all their attention on the meaning of words and sentences. First of all, they try to achieve a total understanding of a text and then move toward detailed aspects of reading comprehension. Grellet (1981, p. 8) stipulates that 'reading is an active skill ... It constantly involves guessing, predicting, checking and asking oneself questions'. Day and Park (2005), under the influence of Pearson and Johnson (1972) and Nuttall (1996), propose and discuss a taxonomy of six types of comprehension in teaching reading and developing material for teaching foreign language reading. Their taxonomy of comprehension includes making inferences through which L2 learners go beyond the literal understanding of a text and combine it with their own knowledge and intuitions to comprehend indirectly mentioned information present in the text. Inference making is considered as a cognitive reading strategy which helps learners accomplish the reading task (Chamot \& O'malley, 1996). As Carrell (1984) states the majority of existing information in a text is not conveyed directly as the literal meaning and implied information becomes intelligible by inference making. It seems inference making stands at the heart of the comprehension. To fill in the omitted details from a text, constant and extensive involvement of readers and listeners to make a comprehensive representation of what they are reading or listening appears inevitable (Dole, Duffy, Roehler, \& Person, 1991).

In addition to inference-making ability, effective in both critical thinking and reading comprehension, the evaluation-making ability as an important factor in both arena comes to play an important role. Hypotheses formulation and evaluation of existing information in the text initiate a constructive cognitive process through which meaning comprehension and knowledge expansion come to be possible (Baretta, Tomitch, MacNair, Lim, \& Waldie, 2009). Grab (2009) maintains that reading comprehension is the readers' ability to combine new 
information with their background knowledge, to interpret the author's viewpoints, to synthesize information from a variety of sources, to evaluate and understand a written text based on intended purpose of reading.

Inductive and Deductive Reasoning, two important constituents of Critical Thinking, construct two basic foundations of generalization and play key roles in first and second language learning. A general law, rule or conclusion which comes to being from specific instances originates from inductive reasoning, however, deductive reasoning allows us from a general principle infer specific instances. In first language acquisition (FLA) or second language acquisition (SLA) in natural and untutored environments, when learners should infer certain rules and meaning from all the existing available data, inductive process comes to help them to learn those rules implicitly, with no explicit capacity to express them. When it comes to language learning in classroom contexts, deductive reasoning provides learners with explicit access to rules and meaning which requires subsequent attention to their instances (Brown, 2014).

Specific thinking skills which seem more influential for learning particular language skills are essential in some language courses. For instance, making use of critical thinking skills seems to be basic requirement when an L2 learner is supposed to write an argumentative essay. The essay should enjoy logical presentation through providing clear argumentation and the validation of proposed ideas, claims, and references. In a similar vein, participation in class discussions involves learners to raise questions and evaluate others' viewpoints. Applying critical thinking in language courses can help them to reach this end (Alnofaie, 2013). Now, the question that may come into mind is: Is a competent L2 learner necessarily a critical thinker, or is a critical thinker necessarily a competent L2 learner?

\section{Narratives and Critical Thinking Skills}

Bean (1996) put under consideration the ability of thinking critically as a teachable skill and Iakovos (2011) argues that the ability to think critically seems not to be organized and developed spontaneously and naturally. Lazere (1987, p. 3) states that 'literature--properly reunified with rhetoric and composition--is the single academic discipline that can come closest to encompassing the full range of mental traits currently considered to comprise critical thinking.' He maintains that literature through literal and figurative language accompanied by syntactic and structural complexity has the necessary capacity to engage students in mature moral reasoning to make them sensitive to possible existing ambiguities, association between variety of viewpoints and various aspects of form and meaning. It seems that providing an appropriate context which develops facilities for dialectical interaction between divergent points of view is of high necessity for sufficient and adequate exercises of critical thinking (Paul, 1981). Meanwhile, narrative texts as an important type of literary texts, in ESL/EFL contexts, appear to be able to engage their readers in critical and dynamic interaction with authors' perspectives, language, characters' functions, implicit and explicit ideas, and inferences concerning the content of the plots.

Bakhtin (1975 cited in Atkinson \& Mitchell, 2010) elucidates that narratives, compared to non-narratives, make use of fairly complex and implied language that make possible the generation of more space for different interpretations, explanations, and argumentations. Using narratives in EFL/ESL contexts can provide Language learners with opportunities in 


\section{Ml Macrothink}

Education and Linguistics Research ISSN 2377-1356 2016, Vol. 2, No. 1

which learners through confrontation with diversity of interpretations, explanations, and argumentations may reach a better self-awareness and higher levels of CT skills. Several articles and books have been published in which the psychological aspects of narratives and the importance of narratives in thinking and experiencing have been taken into consideration (Bruner 1986, 1990, 1996; Donald 1991; Hardy 1978; Harrison, 2004; László, 2008). According to Bruner (1986), there exist two kinds of psychological domains, or, as he supposes, two sceneries come into sight simultaneously in each story. The first one, scenery of action, embraces the cases of action including actor, intention or goal, situation, means, etc. The second domain, the scenery of consciousness, states what the participants of the action think, know and feel, or what they do not know, think and feel. Being so, then, the concurrent presence of these two sceneries of narrative not only assumes that stories do not merely give an account of what has happened but also they outline the psychological perspectives that exist behind the curtain of events and persuade their readers to use their thinking skills to reach a better understanding about many things which are left unexplained in stories.

According to Or (1995), exclusion of literary texts from EFL textbooks and filling them with written passages and dialogues creating a context in which a certain structure can be made to occur with a fair degree of frequency, irrespective of whether or not the usability of such frequency in real world communication may exist, do not persuade EFL students to use their logical reasoning and analytical thinking to raise any questions and make interpretations or extrapolations. Non-narrative texts display and portray no complication and ambiguity to deal with through negotiation, argumentation, and interpretation when meanings, within the text, are clear. Put it differently, Or (1995, p. 186) argues that 'learners are not required to treat texts as discourse, where they interpret and negotiate language. Language is presented in a way that makes minimal demands on effort and thought'. In this respect, Swaffar, Arens and Byrnes (1991) claim that reading purely descriptive texts in ESL contexts will not be followed by an expected success. They state that part of the reason is that descriptive texts with no rhetorical illocution will not stimulate ESL students to use their thinking abilities to analyze and interpret the implicit information within the text, since there is no such a thing. Gray (1960, cited in Alderson, 2000 p.7) makes distinction between three levels of reading consisting of reading 'the lines' which refers to the literal meaning of a text, reading 'between the lines' which goes back to the inferred meaning, and reading 'beyond the lines' which accounts for the readers' critical evaluations of text. Short narratives are types of literary genre that leaves a lot of things unsaid leading to further implications for readers. Thus, it heightens students' sensitivity to the hidden aspects and implied meanings existing at the heart of the text (Khatib, Rezaei \& Derakhshan 2011). Ghasemi and Hajizadeh (2011, p. 69) stated clearly that 'while in reading non-literary material students learn to read the lines and decode the meaning, in reading short stories they learn to read between the lines.'

Hawkins (2012) conducted a study of the relationship among voluntary reading, academic achievement, and critical thinking skills of 117 students (48 males and 69 females) enrolled in seven sections of undergraduate English-four sections of sophomore-level English and three sections of junior-level English at Mt. English College. The findings of the study showed that between critical thinking and voluntary reading, and between college Grade Point Average (GPA) and each score on the California Critical Thinking Skills Test (CCTST' 
total score and all five subscales' scores) there exists statistically a significantly positive relationship. Tung and Chang (2009) through an investigation on the effect of literature reading on 12 ( 10 females and 2 males) Taiwanese EFL learners' CT skills found that the use of literature in EFL context had a positive effect on EFL learners' CT ability in general and their analysis ability in particular. Although the number of participants in this study was not statistically enough and consequently the study's results suffered from lack of sufficient reliability, the study could act as an encouragement for further research in this respect.

Ahmadian and Pashangzadeh (2013) found that to make use of narrative texts vs. non-narratives enjoys significant priority in improvement and enhancement of EFL learners reading comprehension ability. They have speculated that further increase in Narrative group's reading comprehension scores might be the consequence of participants' cognitive analytical abilities development under the influence of using narrative texts as tasks of elicitation. They believe that in dealing with narratives more effort is needed on the part of readers to explore hidden and implicit aspects of these kinds of texts. If so, then providing EFL/ESL learners with proper short narratives can create an appropriate context through which lively and thoughtful class discussions will be provoked. In this way learners will be encouraged to utilize a number of thinking skills including analytical, problem-solving, creative, and reflective thinking skills. Activation of mentioned thinking skills through the use of narrative texts may pave the way for CT development in EFL/ESL contexts.

Some scholars believe in narrative nature of all human knowledge (Schank \& Abelson, 1995). Roche and Sadowsky (2003) argue that all the available evidence in the realm of neurology and psychology comes to the conclusion that thinking follows a narrative structure. Concepts that are transmitted through stories go far beyond the ideas' explanations through logic and analysis and indeed have the capacity to be imprinted into human minds. Narrative psychologists like László (2008) refer to the ubiquitous nature of narrative and maintain that its presence in everywhere and every time is enlightened by the fact that narratives are included in social life. In this respect, because of the pervasive nature of narratives and their presence in all personal, social, and psychological dimensions of human life on the one hand, and their potentials for enhancing individual's creative thinking ability on the other, the researchers of the present study were on intention to investigate possible effects of using narratives vs. non-narratives as tasks of elicitation on EFL learners' critical thinking abilities.

\section{The Present Study}

\subsection{Objective}

As seen, regardless of almost rich literature on the advantages of using narratives in EFL/ESL contexts, the effects of this trend on the development of L2 learners' CT skills have not been touched upon as it deserves. It was thus that the present study was designed to investigate the effect of using short narratives in EFL contexts, as tasks of elicitation, on EFL learners' CT skills. In this respect, the research attempted to answer the following questions:

- Does the use of short narratives, as tasks of elicitation, have any significant effect on EFL learners' CT skills?

- Does the use of short non-narratives, as tasks of elicitation, have any significant effect on EFL learners' CT skills? 
To provide the research questions with an objective answers, the following null hypotheses were formulated to be tested out:

- The use of short narratives, as tasks of elicitation, has no significant effect on EFL learners' CT skills.

- The use of short non-narratives, as tasks of elicitation, has no significant effect on EFL learners' CT skills.

\section{Method}

\subsection{Participants}

For the purpose of the study, 59 undergraduate Persian speaking EFL learners (male and female), aged 19-23, and majoring in English translation at Arak University, Iran, were asked for participation. Their homogeneity in language proficiency and CT skills was measured through the Oxford Placement Test (OPT) and the California Critical Thinking Skills Test (CCTST), respectively. Taking into consideration the OPT results, there appeared no extreme points and outliers. Concerning CCTST results, 54 participants whose scores ranged from 8 to 15 , approximately one standard deviation (2.88) on either side of mean score (11.67) were selected and put into two intact experimental and control groups (hereafter, Narrative and Non-narrative groups in that order). There were 27 participants in each group.

\subsection{Instrumentation}

California Critical Thinking Skills Test (CCTST), Form B, was used as both pretest and post-test. The test encompasses 34 multiple-choice items, each item follows by four or five alternatives which allow a test taker to assess the core critical thinking skills regarded to be essential elements in association with baccalaureate general education including Evaluation, Analysis, Inference, Deductive Reasoning, and Inductive Reasoning. No discipline-specific knowledge is required to do the test.

\subsection{Tasks of Elicitations}

Careful selection and appropriate use of narrative and non-narrative texts with certain qualities were part of the study. Regarding the selection phase, in Narrative group, each of the students was required to select five short narratives (short stories) based on her/his interest. As Fludernik (2009, p. 6) states, 'A narrative is a representation of a possible world in a linguistic and/or visual medium, at whose center there are one or several protagonists of an anthropomorphic nature who are existentially anchored in a temporal and spatial sense and who (mostly) perform goal directed actions.' The most important distinction between narrative and non-narrative texts lies at the presence of protagonist/s in narratives allowing their readers, through a process which is called 'Transportation' (Green \& Brock, 2002), experience an emotional and mental journey into the fictional world and the life of the protagonist/s. Concerning the length of the texts, each text was determined to range between 1500 and 2000 words. Such a length, neither too long nor too short, does not turn the reading process to a boring task on the one hand, and, on the other, does not make it appear trivial in the eyes of students. Non-narrative group was provided with non-narrative texts which, again, were chosen based on students' interests and needs. The texts were tried to be as lengthy as possible to the narrative ones and covering various topics such as History, Social Issues, Sciences, Education, Humanities, and Business. 


\subsection{Procedure}

As mentioned earlier, the homogeneity of participants in general language proficiency and in CT skills were established based on the OPT and CCTST respectively. Our treatment sessions in both Narrative and Non-narrative groups were broadly based on practical applications of communicative reading strategies. Krashen and Terrell (1983) outline communicative reading strategies through which readers (a) read for meaning, (b) do not look up every word, (c) predict meaning, and (d) use context to guess the meaning of unknown words. To fire up participants' CT skills in both Narrative and Non-narrative groups, regarding the nature of the texts, the researchers fired a few questions to stimulate and provoke critical thinking through communication among learners. Some of the questions based on the nature of the used texts are mentioned in Table 1:

Table 1. Questions to fire up CT skills

\begin{tabular}{ll}
\hline Interpretation & What does this mean? \\
& In this context, what was intended by saying/doing that? \\
& How can we make sense out of this (experience, feeling, and statement)? \\
Analysis & Please tell us again your reasons for making that claim. \\
& What is your conclusion/ what is it that you are claiming? \\
Inference & What is your basis for saying that? \\
& Given what we know so far, what conclusions can we draw? \\
& If we believed these things, what would they imply for us going forward? \\
& What are some alternatives we haven't yet explored? \\
Evaluation & How credible is that claim? \\
& How strong are those arguments? \\
& How confident can we be in our conclusion, given what we now know? \\
Explanation & Please take us through your reasoning one more time? \\
& Why do you think that (was the right answer/ was the solution)? \\
& How would you explain why this particular decision was made?
\end{tabular}

Source: Facione (2013, p. 8).

Learners in Narrative group were required to read the selected narrative texts during the treatment sessions. In each session, four or five learners were supposed to provide the class with a summary of what they had read. While Non-narrative group followed a similar procedure, non-narrative texts were used for them. The narratives and non-narratives were used as a vehicle for classroom communication, not just as the object of the study, and teaching was subordination to learning process. In other words, attempts were made to encourage the learners to be autonomous in making their own choices when analyzing, interpreting, negotiating, and evaluating the ideas posed to discuss through reading the narrative and non-narrative texts. In this respect, the ideas of Vygotsky (1978), within the framework of Communicative Approach, regarding the social nature of learning had been embraced, and as a social process, students were encouraged to help each other when 


\section{Al Macrothink Institute ${ }^{\mathrm{TM}}$}

someone was experiencing difficulty. This was done in order to highlight and emphasize the cooperative manner rather than a competitive one as a means of help to reduce and mitigate the level of anxiety that is experienced by EFL learners in classroom settings. In this respect, learners were supposed to listen to the others' ideas, comments and perspectives in a non-defensive manner. Treatment period devoted to this study encompassed 12 sessions through 12 weeks, each session met for nearly 100 minutes. As a final point, once again, the participants were given the CCTST as post-test.

\section{Data Analysis and Results}

\subsection{Within Group Comparisons (Narrative Group)}

A paired-samples t-test was performed to measure the possible change in the learners' CCTST with its subscales scores (Evaluation, Analysis, Inference, Deductive, and Inductive Reasoning) from the pretest to the post-test in Narrative group. Based on Tables 2 and 3, there exists a statistically significant difference (increase) in CCTST mean scores from the pretest $(M=11.37, \mathrm{SD}=2.16)$ to the post-test $(\mathrm{M}=13.48, \mathrm{SD}=2.91), \mathrm{t}(26)=-4.25, \mathrm{p}=.00<.05$ (two-tailed). The mean increase in CCTST scores (from the pretest to the post-test) was 2.11 with a $95 \%$ confidence interval ranging from -3.13 to -1.09 . Given our Eta squared value of .40 , we can argue that there was a large effect size, with a substantial difference in the CCTST scores obtained before and after the intervention.

Regarding CCTST subscales including Evaluation, Analysis, Inference, Deductive Reasoning, and Inductive Reasoning, the tabulated information, in Tables 2 and 3, shows that there is an increasingly statistical difference in mean scores from the pretest to the post-test. The calculated Eta squared statistics concerning Evaluation (.15), Analysis (.14), Deductive Reasoning (.20), and Inductive Reasoning (.22) indicates a large effect size. In association with Inference the Eta squared statistics (.07) indicates a moderate effect size.

In general, according to the mentioned results, one might be tempted to infer that there exists a significant relationship between using short narratives in EFL classes and improvement of EFL learners' CT skills in general and its subscales including Evaluation, Analysis, Deductive Reasoning, and Inductive Reasoning with an exception of Inference in particular. 
Table 2. Paired samples statistics (Narrative Group)

\begin{tabular}{llllcc}
\hline & & Mean & N & Std. Deviation & Std. Error Mean \\
\hline CCTST & Pretest & 11.37 & 27 & 2.16 & .41 \\
Evaluation & Post-test & 13.48 & 27 & 2.91 & .56 \\
& Pretest & 5.00 & 27 & 2.00 & .38 \\
Analysis & Post-test & 5.74 & 27 & 1.45 & .28 \\
& Pretest & 3.14 & 27 & 1.53 & .29 \\
Inference & Post-test & 3.92 & 27 & 1.29 & .24 \\
& Pretest & 3.22 & 27 & 1.18 & .22 \\
Deductive & Post-test & 3.74 & 27 & 1.53 & .29 \\
Reasoning & Pretest & 5.25 & 27 & 1.22 & .23 \\
Inductive & Post-test & 6.37 & 27 & 2.04 & .31 \\
Reasoning & Pretest & 4.55 & 27 & 1.62 & .26 \\
\hline
\end{tabular}

Table 3. Paired samples test (Narrative Group)

\begin{tabular}{|c|c|c|c|c|c|c|c|c|}
\hline & \multirow[t]{2}{*}{ Mean } & \multirow[t]{2}{*}{ S.D } & \multicolumn{2}{|c|}{$\begin{array}{c}95 \% \text { Confidence Interval } \\
\text { of the Difference }\end{array}$} & \multirow[t]{2}{*}{$\mathrm{t}$} & \multirow[t]{2}{*}{$\mathrm{df}$} & \multirow{2}{*}{ 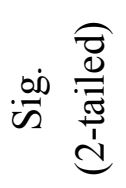 } & \multirow{2}{*}{ 茎 } \\
\hline & & & Lower & Upper & & & & \\
\hline$C C T S T^{*}$ & -2.11 & 2.57 & -3.13 & -1.09 & -4.25 & 26 & .00 & .40 \\
\hline Evaluation * & -.74 & 1.78 & -1.44 & -.03 & -2.15 & 26 & .04 & .15 \\
\hline Analysis * & -.77 & 1.90 & -1.53 & -.02 & -2.11 & 26 & .04 & .14 \\
\hline Inference * & -.52 & 1.82 & -1.24 & .20 & -1.47 & 26 & .15 & .07 \\
\hline $\begin{array}{c}\text { Deductive } \\
\text { Reasoning* }\end{array}$ & -1.11 & 2.20 & -1.98 & -.23 & -2.61 & 26 & .01 & .20 \\
\hline $\begin{array}{c}\text { Inductive } \\
\text { Reasoning* }\end{array}$ & -.88 & 1.69 & -1.55 & -.21 & -2.72 & 26 & .01 & .22 \\
\hline
\end{tabular}

*On Pretest and Post-test.

\subsection{Within Group Comparisons (Non-narrative Group)}

Next, a paired-samples t-test was conducted to measure the possible amount of change in the participants' CCTST and its subscales scores from the pretest to the post-test in Non-narrative group. Based on Tables 4 and 5, there exists no statistically significant difference in CCTST mean scores from the pretest $(\mathrm{M}=11.11, \mathrm{SD}=2.60)$ to the post-test $(\mathrm{M}=10.96, \mathrm{SD}=2.71), \mathrm{t}(26)$ $=.26, \mathrm{p}=.79>.05$ (two-tailed). The mean decrease in CCTST scores (from the pretest to the 


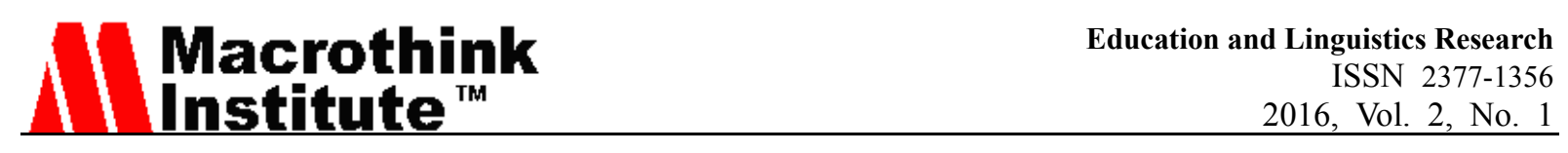

post-test) was .14 with a $95 \%$ confidence interval ranging from -1.01 to 1.30 . The Eta squared statistics (.002) indicates a very small/almost no effect size.

In the case of CCTST subscales including Evaluation, Analysis, Inference, Deductive Reasoning, and Inductive Reasoning, presented statistics, through Tables 4 and 5, reveals that there exists a statistically non-significant difference (increase) in mean scores from the pretest to the post-test. The Eta squared statistics in relation to Evaluation (.04), Analysis (.05), Inference (.00), and Deductive Reasoning (.03) indicates small and very small effect size. Regarding Inductive Reasoning the Eta squared statistics (.10) indicates a moderate effect size.

As a whole, consistent with the stated results, one may come to infer that there is not any significant relationship between using non-narrative texts in EFL classes and development of EFL learners' CT skills in general and its subscales including Evaluation, Analysis, Inference, Deductive Reasoning, and Inductive Reasoning, in particular.

Table 4. Paired samples statistics (Non-narrative Group)

\begin{tabular}{cccccc}
\hline & & Mean & N & Std. Deviation & $\begin{array}{c}\text { Std. Error } \\
\text { Mean }\end{array}$ \\
\hline \multirow{2}{*}{ CCTST } & Pretest & 11.11 & 27 & 2.60 & .50 \\
& Post-test & 10.96 & 27 & 2.71 & .52 \\
Evaluation & Pretest & 4.29 & 27 & 1.70 & .32 \\
& Post-test & 4.66 & 27 & 2.00 & .38 \\
\multirow{2}{*}{ Analysis } & Pretest & 3.59 & 27 & 1.52 & .29 \\
& Post-test & 3.18 & 27 & 1.41 & .27 \\
& Pretest & 3.14 & 27 & 1.45 & .28 \\
Deductive Reasoning & Post-test & 3.11 & 27 & 1.33 & .25 \\
& Pretest & 6.00 & 27 & 2.03 & .39 \\
& Post-test & 5.66 & 27 & 1.64 & .31 \\
Inductive Reasoning & Pretest & 3.51 & 27 & 1.69 & .35 \\
\hline
\end{tabular}


Table 5. Paired samples test (Non-narrative Group)

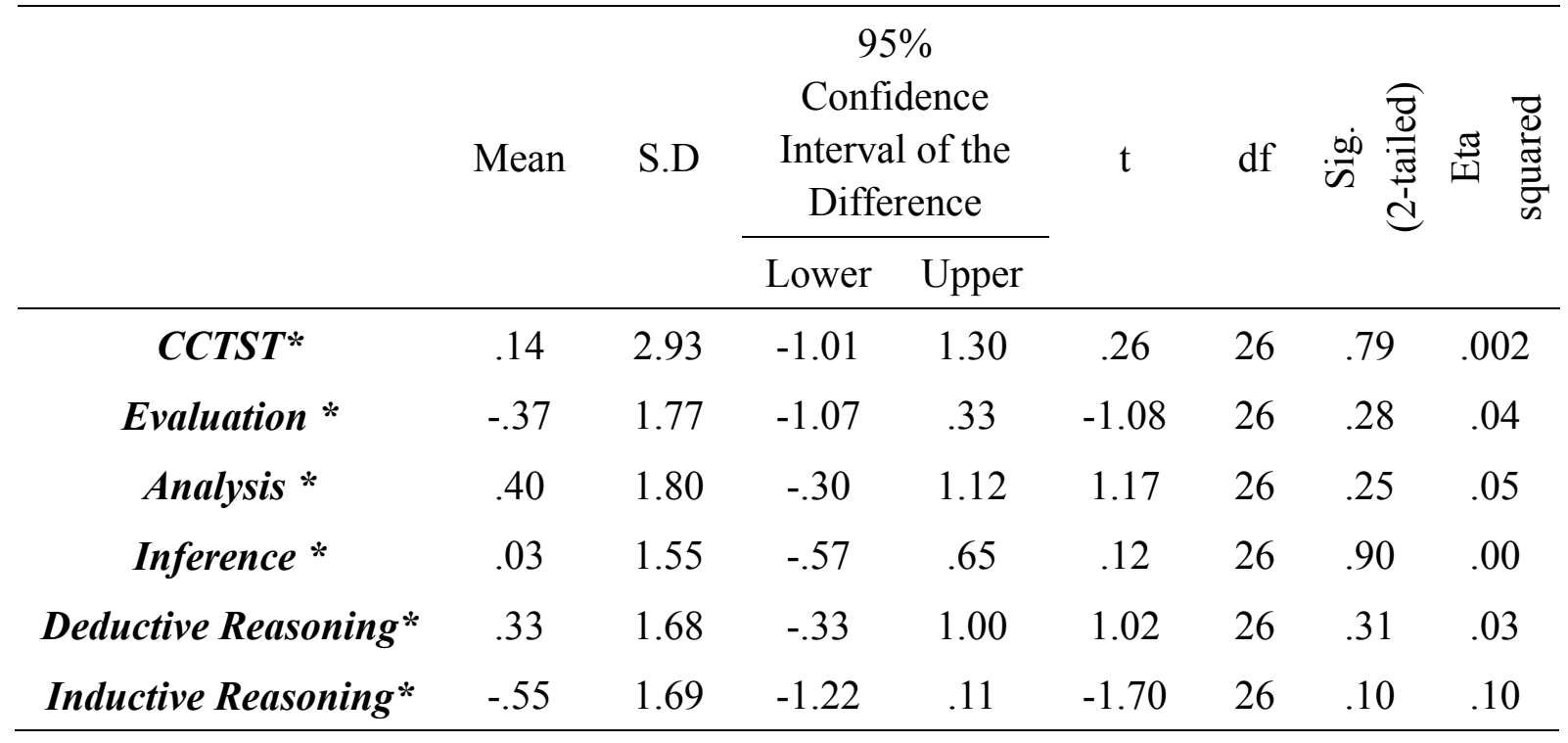

*On Pretest and Post-test.

\subsection{Between Group Comparisons (Narrative and Non-narrative Groups'Pretests)}

An independent-samples t-test was conducted to compare the CCTST scores (in the pretests) and its sub-scales for Narrative and Non-narrative groups. According to the presented information in Tables 6 and 7, there was not a statistically significant difference in CCTST mean scores in general for Narrative group $(M=11.37, S D=2.16)$ and Non-narrative group, $M=11.11, S D=2.60 ; t(52)=.39, p=.69>.05$ (two-tailed) on the pretest occasions. The mean difference $=.25(95 \%$ Confidence Interval) was not significant (eta squared $=.002$ showing almost no effect size).

In association with CCTST subscales including Evaluation, Analysis, Inference, and Deductive Reasoning, existing statistics, in Tables 6 and 7, tell that the mean scores, in the pretests, for Narrative group and Non-narrative group show statistically non-significant difference. The Eta squared statistics for Evaluation (.03), Analysis (.02), Inference (.00), and Deductive Reasoning (.04) points to small and very small effect size. For Inductive reasoning the mean difference $=1.03$ was significant and eta squared $=.09$ indicates a moderate effect size.

Based on the mentioned results, regarding the indices of independent-samples t-test, we can see that both of the experimental and control groups in relation to CT skills in general (CCTST' performance) and its subscales including Evaluation, Analysis, Inference, and Deductive Reasoning in particular with an exception of Inductive Reasoning were homogeneous. 
Table 6. Group statistics (Pretests- Narrative and Non-narrative Groups)

\begin{tabular}{lllllc}
\hline \multirow{2}{*}{ CCTST } & Groups & Mean & N & S.D & Std. Error Mean \\
\multirow{2}{*}{ Evaluation } & Narrative & 11.37 & 27 & 2.16 & .41 \\
& Non-narrative & 11.11 & 27 & 2.60 & .50 \\
Analysis & Narrative & 5.00 & 27 & 2.00 & .38 \\
& Non-narrative & 4.29 & 27 & 1.70 & .32 \\
Inference & Narrative & 3.14 & 27 & 1.53 & .29 \\
& Non-narrative & 3.59 & 27 & 1.52 & .29 \\
Deductive Reasoning & Narrative & 3.22 & 27 & 1.18 & .22 \\
& Non-narrative & 3.14 & 27 & 1.45 & .28 \\
Inductive Reasoning & Narrative & 5.25 & 27 & 1.22 & .23 \\
& Non-narrative & 6.00 & 27 & 2.03 & .39 \\
& Narrative & 4.55 & 27 & 1.62 & .31 \\
& Non-narrative & 3.51 & 27 & 1.69 & .32 \\
\hline
\end{tabular}

Table 7. Independent samples test (Pretests- Narrative and Non-narrative Groups)

Levene's

Test for

Equality of

t-test for Equality of Means

Variances

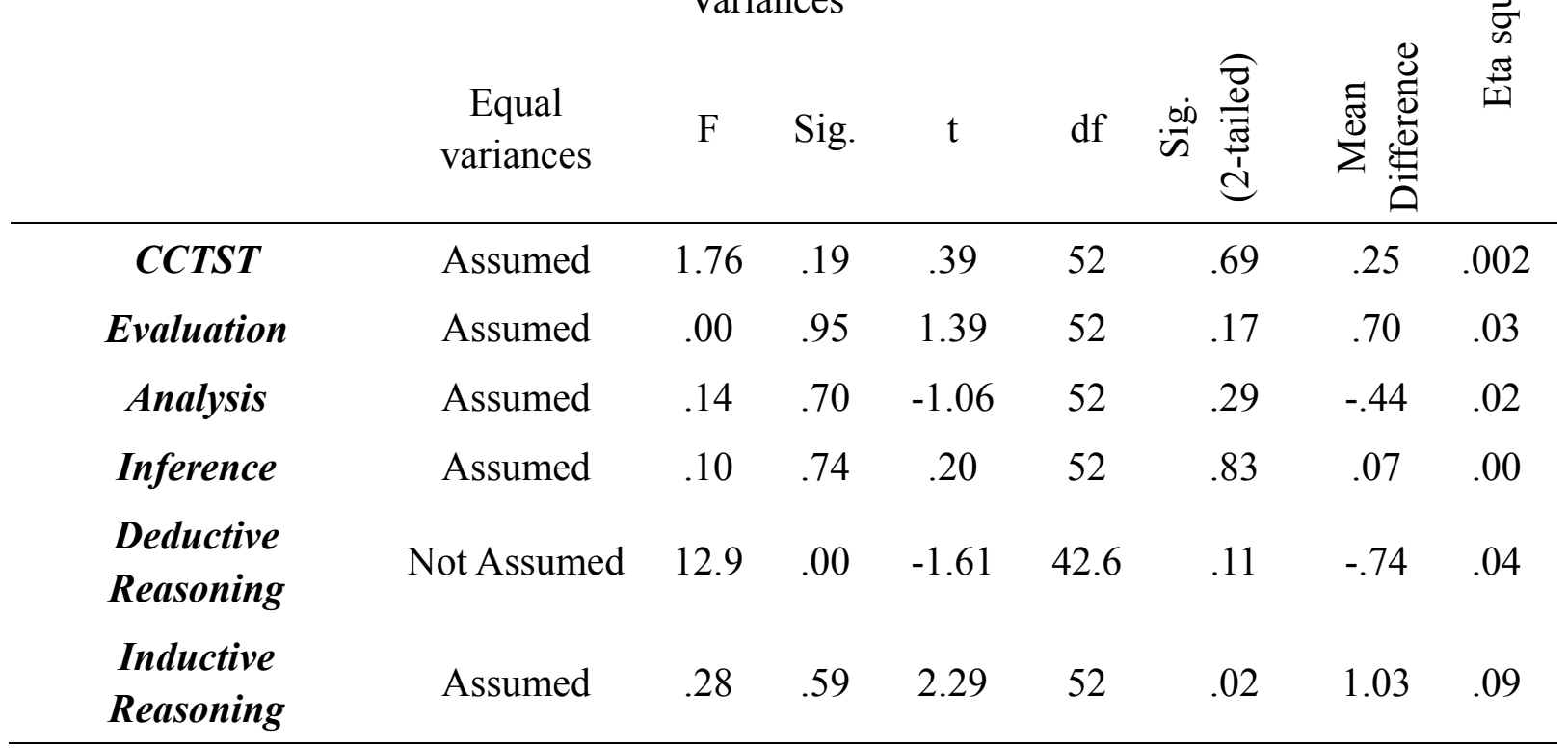

6.4 Between Group Comparisons (Narrative and Non-narrative Groups'Post-tests)

Finally, an independent-samples t-test was run to compare the CCTST scores (in post-tests) and its sub-scales for Narrative and Non-narrative groups. Tables 8 and 9 show that there was 
a statistically significant difference in CCTST mean scores in general for Narrative group ( $M$ $=13.48, S D=2.91)$ and Non-narrative group, $M=10.96, S D=2.71 ; t(52)=3.28$, $p=.002<.05$ (two-tailed) in post-test occasion. The mean difference $=2.51(95 \%$ Confidence Interval) was significant (eta squared $=.17$ which is an indication of large effect size).

Regarding CCTST subscales, Evaluation and Analysis, offered information, Tables 8 and 9, illustrates statistically significant differences in mean scores between Narrative group and Non-narrative group. The obtained Eta squared statistics concerning Evaluation (.08) and Analysis (.07) shows a moderate effect size.

In relation to the two other CCTST subscales, Inference and Deductive Reasoning, there were not statistically significant differences in mean scores for Narrative group and Non-narrative group (post-tests). The Eta squared statistics for Inference (.04) and Deductive Reasoning (.03) indicated a small effect size.

Table 8. Group statistics (Posttests/Narrative and Non-narrative Groups)

\begin{tabular}{lllllc}
\hline \multirow{2}{*}{ CCTST } & Groups & Mean & N & S.D & Std. Error Mean \\
\multirow{4}{*}{ Evaluation } & Narrative & 13.48 & 27 & 2.91 & .56 \\
& Non-narrative & 10.96 & 27 & 2.71 & .52 \\
Analysis & Narrative & 5.74 & 27 & 1.45 & .28 \\
& Non-narrative & 4.66 & 27 & 2.00 & .38 \\
\multirow{4}{*}{ Inference } & Narrative & 3.92 & 27 & 1.29 & .24 \\
& Non-narrative & 3.18 & 27 & 1.41 & .27 \\
Deductive & Narrative & 3.74 & 27 & 1.53 & .29 \\
Reasoning & Non-narrative & 3.11 & 27 & 1.33 & .25 \\
Inductive Reasoning & Narrative & 5.44 & 27 & 1.39 & .39 \\
& Narrative & 6.37 & 27 & 2.04 & .26 \\
& Non-narrative & 5.66 & 27 & 1.64 & .35 \\
\hline
\end{tabular}


Table 9. Independent samples test (Posttests-Narrative and Non-narrative Groups)

\begin{tabular}{|c|c|c|c|c|c|c|c|c|}
\hline & & $\begin{array}{r}\text { Leve } \\
\text { for } \mathrm{E} \\
\mathrm{Va}\end{array}$ & $\begin{array}{l}\text { Test } \\
\text { ity of } \\
\text { ces }\end{array}$ & t-test & r Equa & lity o & Keans & 己ֶ, \\
\hline & $\begin{array}{c}\text { Equal } \\
\text { variances }\end{array}$ & $\mathrm{F}$ & Sig. & $\mathrm{t}$ & df & $\begin{array}{l}\stackrel{\overparen{d}}{\frac{\vec{t}}{4}} \\
\stackrel{d}{d}\end{array}$ & 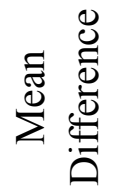 & 焉 \\
\hline CCTST & Assumed & .50 & .48 & 3.28 & 52 & .002 & 2.51 & .17 \\
\hline Evaluation & Assumed & 3.04 & .08 & 2.25 & 52 & .02 & 1.07 & .08 \\
\hline Analysis & Assumed & .58 & .44 & 2.00 & 52 & .05 & .74 & .07 \\
\hline Inference & Assumed & .48 & .49 & 1.60 & 52 & .11 & .62 & .04 \\
\hline $\begin{array}{l}\text { Deductive } \\
\text { Reasoning }\end{array}$ & Assumed & .97 & .32 & 1.39 & 52 & .16 & .70 & .03 \\
\hline Inductive Reasoning & Assumed & 1.65 & .20 & 3.06 & 52 & .003 & 1.37 & .15 \\
\hline
\end{tabular}

\section{Discussion}

This study investigated whether the use of short narratives, in comparison with short non-narratives, in EFL contexts has any significant positive effect on EFL learners' CT skills. The main findings based on data analysis are discussed and elaborated as follows:

The obtained statistical results showed that the use of narrative texts as tasks of elicitation in Narrative group led to a statistically significant positive development in EFL Learners' CT skills. Results of statistical analysis showed that there existed a statistically and increasingly significant difference in CCTST mean scores in general and its subscales in particular (including Evaluation, Analysis, Deductive, and Inductive Reasoning with an exception of Inference) from the pretest to the post-test. Regarding Non-narrative group, the results of statistical analysis indicated that there was statistically significant difference in neither CCTST mean scores in general nor its subscales in particular from the pretest to the post-test. Concerning between group comparisons, statistical results showed significant out-performance of Narrative group in the post-test compared to Non-narrative group in CCTST in general and its subscales including Evaluation and Analysis in particular. Relating to the other subscales including Inference, Deductive Reasoning, and Inductive Reasoning, despite the existence of difference in mean scores between Narrative and Non-narrative groups, the differences were not statistically significant.

Although supporters of learner oriented instructions criticize didactic method of teaching, mentioning that teacher centered approaches only provides the ground for rote learning instead of promotion of critical thinking skills (Scheffler, 1973; Malone, 2008), the findings of the study shows that, while learner oriented instructions pave the way for critical thinking development, instructional materials may play a more important role in this regard. Even though the use of learner oriented instructions is absolutely necessary to improve EFL 


\section{Ml Macrothink}

learners' critical thinking skills, however, is not enough to do so. As seen, despite the use of learner oriented approaches in Non-Narrative group, no statistically significant progress in association with EFL learners' critical thinking skills was observable.

Ahmadian and Pashangzadeh's (2013) findings indicated narratives' superiority compared with non-narratives in enhancing EFL learners' reading comprehension ability. They speculated that further development in Narrative group's reading comprehension scores might be the result of Narrative group participants' cognitive analytical abilities development under the influence of using narrative texts. As previously described, Hawkins (2012) found that there is a statistically significant positive relationship between participants' critical thinking scores on the CCTST (total score and all five subscales' scores) and voluntary reading. It seems that EFL learners in a similar way make use of CT skills including Evaluation, Analysis, Inference, Deductive Reasoning, and Inductive Reasoning, to comprehend while reading a text. So, providing EFL learners with proper short narratives within the framework of learner oriented approaches may prepare the necessary contexts in which language teachers will be able to give their language learners more of an opportunity to recall their analytical abilities containing problem-solving, logical inference, creative, and reflective thinking skills to the scene while interacting with narrative texts. As the findings of this study show, the use of short narratives is effective to pave the way toward EFL learners' CT skills improvement.

The findings demonstrate that the use of narrative texts as an important type of literary texts does offer a high potential to increase CT skills among EFL learners. A glimpse at the history of human beings reveals that one unifying characteristic of humane life is stories. In fact, no known humane culture lacks stories. Narratives/stories have almost always been a place of patriotic heroes who have tried to promote the concepts of human excellence through the exhibition of beauties of love, truth, devotion, justice, etc. and denouncement of ambition, betrayal, lies, greed, lust, gluttony, pride, envy, and wrath (Rees 1973; Burgess 1991; Sinkewicz, 2006). As Ahmadian and Pashangzadeh (2014) argue, irrespective of language systems, the mentioned concepts through narratives enjoy high universality and commonality among people of different nations around the world. They believe that 'one of the most important existing variations between narratives and non-narratives can be the narratives' capacity to express these concepts ideally through a plot in which events are associated together chronologically' (p.703). In other words, EFL/ESL learners have already been familiar with narratives/stories through their native language and culture which may enjoy common grounds. If so, then we may assume that the previous familiarity with narratives/stories in first language may act as a positive cross linguistic influence that may lead to activation of cognitive mechanisms in a way that is much more effective than what is done by non-narratives including geographical or historical texts to mention but a few, since much less positive cross linguistic influence in non-narrative texts may be observed.

The previous familiarity with narratives in first language may act as background knowledge in EFL/ESL contexts when language learners deal with narrative texts in L2. In this regard, the previous familiarity may play an important role in reduction of what has been called 'debilitating anxiety' which has negative impact on learning contexts (Alpert \& Haber, 1960; Scovel, 1978). Locken and Norberg (2005) claim that anxiety reduction, in educational 
settings, paves the way toward Critical Thinking enhancement. In this study, statistical results regarding over development of L2 learners' critical thinking skills in Narrative group compared to Non-narrative group's members may be taken as an indication of the lower levels of anxiety under the effect of using narrative texts as elicitation tasks. Observational evidence also confirms and supports reduced communication apprehension in class discussions. Reduction of debilitating anxiety, under the influence of using short narratives, can be one of the possible explanations why Narrative group has had more CT skills' development in comparison with Non-narrative one.

Another characteristic of a good critical thinker concerns the degree to which an individual is cognitively able to tolerate and stay open-minded in confrontation with the ideas and propositions that stand in contradiction with their own system of thinking and structure of beliefs (Meyers, 1986). Reading L2 narratives seems to help L2 learners to free up their minds and their imagination, and provide them with favorable opportunity to put on eyeglasses of L2 speaking people (including authors of narrative texts, protagonists and antagonists) to adopt their perspectives, mannerisms and ideologies to see the world of life from different windows as the target language speaking people may see. Familiarity with L2 culture helps the learners look at the world around and their lives through a different and new window. Consequently, in this way, L2 narrative-readers may learn to move from a self-centered world, whose foundation is rested on stereotypes and limited personal experiences toward a world around them, and enter the realm in which a wealth of values, standpoints and varieties exist. The use of appropriate short narratives/stories in second/foreign language instructional contexts can provide the learners with a new opportunity to learn about the life style and culture of people who speak in the target language. Consequently, positive, friendly, and sympathetic attitude toward the members of L2 culture may be fostered. In this way, L2 narrative readers through self-revelation may develop more emotional, logical, and moral self-awareness which prepares them to abandon those negative attitudes which appear not to work anymore. As Brown (2006) mentions, positive attitudes may lead to increased motivation to learn a second language.

Green and Brock (2000, p. 703) suggest that 'transportation into a story causes people to be less motivated (or less able) to disbelieve any particular conclusion'. Put it similarly, they maintain that because of high transportation and absorption in the world of story, the readers would likely be reluctant to pause and make critical analyses and evaluation of information encountered in the narrative. The findings of this study partially contradict their suggestion and show that reading narrative texts can increases the critical thinking skills.

\section{Conclusions and Implications}

This study was an attempt to investigate possible effects of using short narratives in EFL contexts, as tasks of elicitation, on EFL learners' CT skills. Regarding the statistical outcomes, narrative texts compared to non-narrative ones enjoy high priority to enhance development in EFL learners' CT skills. Moreover, statistical results show that under the influence of using narratives, critical thinking's sub-skills including Inductive Reasoning, Deductive Reasoning, Analysis, and Evaluation indicate statistically noticeable enhancement. However, critical thinking ability in general and its sub-skills under the effect of using non-narratives, as 


\section{Macrothink}

instructional tools, show non-significant change and improvement. Thus, the study concludes that L2 learners' CT skills might be better developed by engaging with narrative texts rather than the more intuitively obvious non-narrative 'argumentative' texts.

The final goal of the study was to build links between the research findings and real EFL educational contexts and put them into practice with the aim of making improvement in L2 learning and teaching conditions. Prevailing EFL educational system in Iran is traditional and teacher centered approaches based on didactic instruction. Didactic instruction can be harmful to students' learning process because students stop thinking critically and do not engage actively in class activities. They merely serve as receivers for whatever information the teacher presents. In addition, the traditional education system purposely introduces certain set of values into students, in which they are prompted to seek correct answers and predetermined interpretations. Being immersed in certain ideologies, students are unlikely to become critical and reflective thinkers (Scheffler, 1973; Malone, 2008). Given the discussed benefits of critical thinking skills in L2 learning contexts, the results of this study may act as an inspirational source for Iranian educational policy makers in association with foreign language learning and teaching programs, syllabus designers, and EFL teachers to deal with the issue not only from a narrative-oriented point of view and provide EFL learners with appropriate narrative texts as applicable content, but also from a learner oriented approach to help them develop their critical thinking abilities within and probably without the context of second/foreign language.

Likewise, the finding of the research might raise general awareness among EFL teachers regarding the significance of CT in EFL classes. Our understanding of the components of CT skills, as language teachers, may, to a large extent, lead to a better understanding of eclectic nature of language teaching that there is no single theory or approach which will provide a magic pedagogical formula to cover all learners' needs in all contexts. In this way, better understanding of CT skills may leave a positive effect on L2 teachers' choices of their teaching methodologies and help them take into consideration the value of different models, theories and research findings as well.

Last but not least, the findings of the present research may make a positive contribution to the development of CT skills in first language acquisition contexts through efficient use of appropriate short narratives/stories by parents, preschool and elementary school teachers. However, for making more accurate generalization, further research may optimistically provide more evidence.

\section{Acknowledgment}

The authors of the article remember with a deep sense of gratitude Dr. Masood Keshavarz for his generous support and close cooperation during the course of data collection for this research. We also would like to acknowledge and extend our heartfelt gratitude to Dr. Seyed Mohsen Shahtaheri for his vital support and help. Sincere thanks to all undergraduate students who participated willingly and kindly in this research project.

\section{References}

Ahmadian, M., \& Pashangzadeh, A. (2013). A Study of the Effect of Using Narratives on Iranian EFL Learners' Reading Comprehension Ability. International Journal of Applied 
$\begin{array}{lllll}\text { Linguistics } \quad \& \quad \text { English } & \text { Literature, } & 2(3), & 153-162 .\end{array}$ http://dx.doi.org/10.7575/aiac.ijalel.v.2n.3p.153

Ahmadian, M., \& Pashangzadeh, A. (2014). An Investigation of the Effects of Text Variation on EFL Learners' Reading Comprehension Ability. British Journal of Education, Society \& Behavioural Science, 4(6), 691-707. http://dx.doi.org/10.9734/BJESBS/2014/7767

Alderson , J. C. (2000). Assessing Reading. Cambridge: Cambridge University Press. http://dx.doi.org/10.1017/CBO9780511732935

Alnofaie, H. (2013). A framework for implementing critical thinking as a language pedagogy in EFL preparatory programmes. Thinking Skills and Creativity, 10, 154-158. http://dx.doi.org/10.1016/j.tsc.2013.09.002

Alpert, R., \& Haber, R. N. (1960). Anxiety in academic achievement situations. The Journal of Abnormal and Social Psychology, 61(2), 207-215. http://dx.doi.org/10.1037/h0045464

Atkinson, B., \& Roland, M. (2010). "Why Didn't They Get It?" "Did They Have to Get It?": What Reader Response Theory Has to Offer Narrative Research and Pedagogy. International Journal of Education \& the Arts, 11(7), 1-24.

Baretta, L., Tomitch, L. B., MacNair, N., Lim, V. K., \& Waldie, K. E. (2009). Inference making while reading narrative and expository texts: an ERP study. Psychology \& Neuroscience, 2(2), 137-145. http://dx.doi.org/10.3922/j.psns.2009.2.005

Bean, J. C. (1996). Engaging Ideas: The Professor's Guide to Integrating Writing, Critical Thinking, and Active Learning in the Classroom. San Francisco: Jossey-Bass.

Brookfield, S. (1987). Developing Critical Thinkers: Challenging Adults to Explore Alternative Ways of Thinking and Acting. San Francisco: Jossey-Bass.

Brown, D. H. (2006). Principles of Language Learning and Teaching (5th ed.). New York: Pearson Education ESL.

Brown, H. D. (2014). Principles of Language Learning and Teaching: A Course in Second Language Aquisition (6 ed.). Pearson Education ESL.

Bruner, J. (1986). Actual Minds, Possible Worlds. Cambridge, MA: Harvard University Press.

Bruner, J. (1990). Acts of Meaning. Cambridge, MA: Harvard University Press.

Bruner, J. (1996). The Culture of Education. Cambridge, MA: Harvard University Press.

Burgess, A. (1991). English Literature. London: Logman.

Carrell, P. L. (1984). Inferencing in ESL: Presuppositions and Implications of Factive and Implicative Predicates. Language Learning, 34(1), 1-21. http://dx.doi.org/10.1111/j.1467-1770.1984.tb00993.x

Chamot, A. U., \& O'Malley, J. M. (1996). The Cognitive Academic Language Learning Approach: A Model for Linguistically Diverse Classrooms. The Elementary School Journal, 96(3), 259-273. http://dx.doi.org/10.1086/461827

Day, R. R., \& Park, J.-s. (2005). Developing reading comprehension questions. Reading in a Foreign Language, 17(1), 60-73.

Dole, J. A., Duffy, G. G., Roehler, L. R., \& Pearson, P. D. (1991). Moving from the Old to the New: Research on Reading Comprehension Instruction. Review of Educational Research, 61(2), 239-264. http://dx.doi.org/10.3102/00346543061002239 
Donald, M. (1991). Origins of the Modern Mind: Three Stages in the Evolution of Culture and Cognition. Cambridge, MA: Harvard University Press.

Facione, N., \& Facione, P. (1994). The "California Critical Thinking Skills Test" and the National League for Nursing Accreditation Requirement in Critical Thinking. Millbrae, CA: The Calitbmia Academic Press.

Facione, P. A. (2013). Critical Thinking: What It is and Why it Counts. Insight Assessment, $1-28$.

Ferrett, S. K. (1997). Peak Performance: Success in College and Beyond (2nd ed.). New York: McGraw-Hill.

Fludernik, M. (2009). An introduction to narratology. (P. Häusler-Greenfield, \& M. Fludernik, Trans.) Routledge.

Ghasemi, P., \& Hajizadeh, R. (2011). Teaching L2 Reading Comprehension through Short Story. International Proceedings of Economics Development \& Research, 26, 69-73.

Green, M. C., \& Brock, T. C. (2000). The Role of Transportation in the Persuasiveness of Public Narratives. Journal of Personality and Social Psychology, 79(5), 701-721. http://dx.doi.org/10.1037/0022-3514.79.5.701

Green, M. C., \& Brock, T. C. (2002). In the mind's eye: Transportation-imagery model of narrative persuasion. In M. C. Green, J. J. Strange, \& T. C. Brock (Eds.), Narrative Impact: Social and Cognitive Foundations (pp. 315-341). Mahwah, New Jersey: LAWRENCE ERLBAUM ASSOCIATES.

Grellet, F. (1981). Developing Reading Skills. Cambridge: Cambridge University Press.

Halpern, D. (2003). Thought and knowledge: An Introduction to Critical Thinking (4 ed.). Mahwah, New Jersey: Lawrence Erlbaum Associates.

Hardy, B. (1978). Narrative as a primary act of mind. In M. Meek, A. Warlow, \& G. Barton (Eds.), The Cool Web: The Pattern of Children's Reading. New York: Atheneum.

Harrison, C. (2004). Understanding Reading Development. London: SAGE Publications. http://dx.doi.org/10.4135/9781446215401.n3

Hawkins, K. T. (2012). Thinking and Reading Among College Undergraduates: An Examination of the Relationship between Critical Thinking Skills and Voluntary Reading. (Unpublished doctoral dissertation). University of Tennessee, Knoxville,USA.

Iakovos, T. (2011). Critical and Creative Thinking in the English Language Classroom. International Journal of Humanities and Social Science, 1(8), 82-86.

Jose, J. (2013). Unconventional Materials for Promoting Autonomous Learning Promoting Autonomous Learning. ELT Voices - India, 3(6), 96-113.

Khatib, M., Rezaei, S., \& Derakhshan, A. (2011). Literature in EFL/ESL Classroom. English Language Teaching, 4(4), 201-208. http://dx.doi.org/10.5539/elt.v4n1p201

Krashen, S. D., \& Terrell, T. D. (1983). The natural approach: language acquisition in the classroom. Oxford: Pergamon Press.

Kurfiss, J. G. (1988). Critical Thinking: Theory, Research, Practice, and Possibilities. ASHE-ERIC Higher Education Report No.2,. Washington, DC: Association for the Study of Higher Education. 
Lazere, D. (1987). Critical thinking in college English studies. Washington, DC: ERIC Clearinghouse on Reading and communication skills. (ERIC Document Reproduction Service No. ED 284 275).

László, J. (2008). The Science of Stories: An Introduction to Narrative Pscychology: London: Routledge.

Locken, T., \& Norberg, H. (2005). Reduced Anxiety Improves Learning Ability of Nursing Students Through Utilization of Mentoring Triads. Retrieved March 19, 2015, from https://nursing.byu.edu/Documents/research/abstracts_0506/Locken,\%20Norberg\%20(2005) $\% 20$ Reduced\%20Anxiety\%20Improves\%20Learning\%20Ability\%20of\%20Nursing\%20Stud ents\%20Through.pdf

Malone, D. (2008). Inquiry-Based Early Childhood Teacher Preparation: The Personal Learning Plan Method. Early Childhood Education Journal, 35(6), 531-542. http://dx.doi.org/10.1007/s10643-008-0237-4

Meyers, C. (1986). Teaching students to think critically. San Francisco, California: Jossey-Bass.

Nuttall, C. (1996). Teaching reading skills in a foreign language. Oxford: Heinemann.

Or, W. W. (1995). Reinstating literature in the EFL syllabus. In Kitty P. Y. Wong, \& Christopher F (Eds.), Thinking language: issues in the study of language and language curriculum renewal (pp. 183-192). Green. Hong Kong: Language Centre, Hong Kong University of Science and Technology.

Paul, R. (1981). Teaching Critical Thinking in the 'Strong' Sense: A Focuson Self-Deceptive World Views, and a Dialectical Mode of Analysis. Informal Logic, 4(2), 2-7.

Paul, R. W., Elder, L., \& Bartell , T. (1997). California Teacher Preparation for Instruction in Critical Thinking: Research Findings and Policy Recommendations . Sacramento, California: Foundation for Critical Thinking.

Pearson, P. D., \& Johnson, D. D. (1972). Teaching reading comprehension. New York: Holt, Rinehart \& Winston.

Rees, R. J. (1943). English Literature: An Introduction for Foregin Readers. London: McMillan Education Limited.

Roche, L., \& Sadowsky, J. (2003). The power of stories (I): a discussion of why stories are powerful. International Journal of Information Technology and Management, 377-388. http://dx.doi.org/10.1504/IJITM.2003.004233

Schank, R. C., \& Abelson, R. P. (1995). Knowledge and Memory: The Real Story. In R. Wyer $\mathrm{Jr}$ (Ed.), Knowledge and Memory: the Real Story. Hillsdale, NJ. Lawrence Erlbaum Associates. 1-85.

Scheffler, I. (1973). Reason and teaching. Indianapolis, Indiana: Hackett Publishing Company.

Scovel, T. (1978). THE EFFECT OF AFFECT ON FOREIGN LANGUAGE LEARNING: A REVIEW OF THE ANXIETY RESEARCH. Language Learning, 28(1), 129-142. http://dx.doi.org/10.1111/j.1467-1770.1978.tb00309.x

Smith, R. A. (2002). Challenging Your Preconceptions: Thinking Critically About Psychology 


\section{Macrothink \\ Education and Linguistics Research \\ ISSN 2377-1356 2016, Vol. 2, No. 1}

(2 ed.). Belmont, California: Wadsworth.

Swaffar, J. K., Arens, K., \& Byrnes, H. (1991). Reading for Meaning: An Integrated Approach to Language Learning. Englewood Cliffs, New Jersey: Prentice Hall.

Sinkewicz, R. E. (2006). Evagrius of Pontus: The Greek Ascetic Corpus. Oxford University Press.

Tung, C.-A., \& Chang, S.-Y. (2009). Developing Critical Thinking through Literature Reading. Feng Chia Journal of Humanities and Social Sciences, 19, 287-317.

Üstünlüoğlu, E. (2004). Language Teaching through Critical Thinking and Self-Awareness. English Teaching Forum, 42(3), 2-8.

Vigotsky, L. S. (1978). Mind in Society: The Development of Higher Psychological Processes. M. Cole, V. John-Steiner, S. Scribner, \& E. Souberman (Eds.), Cambridge, MA: Harvard University Press.

Wade, C. (2008). Critical Thinking: Needed Now More Than Ever. In D. S. Dunn, J. S. Halonen, \& R. A. Smith (Eds.), Teaching Critical Thinking in Psychology (pp. 11-22). Wiley-Blackwell. http://dx.doi.org/10.1002/9781444305173.ch2

\section{Copyright Disclaimer}

Copyright reserved by the author(s).

This article is an open-access article distributed under the terms and conditions of the Creative Commons Attribution license (http://creativecommons.org/licenses/by/3.0/). 